\title{
PENDEKATAN SISTEM 2D MODEL STREETER-PHELPS UNTUK MODEL POLUSI SUNGAI
}

(A 2D Systems Approach to River Pollution Modelling)

\author{
RUDY WOLTER MATAKUPAN \\ Staf Jurusan Matematika FMIPA UNPATTI \\ Jl. Ir. M. Putuhena, Kampus Unpatti, Poka-Ambon \\ e-mail: rwmatakupan@yahoo.com
}

\begin{abstract}
Applications to positive 2D system can follow Steeter-Phelps model to river flow model. by modifying the discrete values. mathematical model structure provided by the river flow at time step $t$ is proportional to the length of rivers and water velocity. The variables that influence is Dissolved oxygen (DO) and Biological oxygen demand (BOD), both these variables are calculated by balance considerations equetion with the screening process, the process of reaeration, and the source of BOD established a mathematical model of positive 2D systems
\end{abstract}

Keywords: Positive Systems 2D, Steeter-Phelps model

\section{PENDAHULUAN}

Model ruang bagian dapat dijelaskan melalui proses penyaringan (self-purification) alami dari suatu sungai. Perlu diingat bahwa hipotesis Biokimia berkaitan dengan model klasik Streeter-Phelps (1925), yakni hanya dengan memodifikasi nilai-nilai diskrit kedua ruang dan variabel waktu (time variables).

Masalah kwalitas sungai yang dicemari oleh bahan pengotor, mengendap kedalam sungai sebagai akibat dari aktivitas manusia. Bahan kotoran dan organisme sungai seperti bakteri, alga dan ikan, saling mempengaruhi dalam suatu sistem yang sangat berbelit dari hubungan nutrisi diantara spesis-spesis. Bahan makanan termasuk dalam bahan yang tercemar, teroksidasi dengan cara demikian dan pada akhirnya tercemar pada substansi abiotik, seperti karbonhidrat, nitrat, dan sebagainya.

Tahap pertama dalam membangun suatu model matematika dari proses di atas, yakni menyelidiki variabel-variabel yang relevan dengan masalah-masalah tersebut. Hanya variabel asli yang muncul dalam modelmodel penyaringan kosentrasi larutan oksigen (dissolved oxygen=DO), yang mana juga menentukan suatu kriteria penting untuk kualitas air. Disisi lain, hal itu jelas tidak dapat dimulai dengan variabel bagian untuk setiap pencemaran dan semua kehidupan spesis. Pendekatan sederhana dengan mereduksi variabel bahan campuran ke satu klas dari substansi-substansi oksidasi dan kosentrasi terukur dari reaksi fiksi tersebut, oleh kwantitas oksigen yang diperlukan untuk oksidasi biokimia lengkap (BOD = Biological oxygen demand). Bentuk berbeda model
Ekologis, memberikan gambaran yang eksplisit dari organisme, dimana kehidupan organisme diantara larutan oksigen dan bahan oksidasi sangat mengkwatirkan kelangsungan hidup organisme tersebut.

Di sini akan dianggap bahwa seluruh variasi dari kosentrasi BOD dan DO pada sungai merupakan contoh yang representatif daripada longitudinal untuk model defusi yang tidak dibahas di sini.

\section{TINJAUAN PUSTAKA}

Sistem linear diskrit 2D dalam bentuk pertama kali diperkenalkan oleh matematikawan Italy, Ettore Fornasini dan Giovanni Marchesini (1978) dengan artikelnya StateSpace Realization Theory of Two-Dimensional Filters. Semenjak itu berbagai tulisan termuat di berbagai jurnal mengenai model matematik seperti pada tahun 1991, Ettore Fornasini kembali menulis tentang A $2 D$ systems approach to river pollution modelling. Suatu karya yang fenomenal tentang aplikasi sistem positif 2D. Dengan berbagai pustaka, penulis menguraikan tentang salah satu aplikasi model sistem 2D ini.

\section{HASIL DAN PEMBAHASAN}

\section{Struktur Model}

Tahap pertama untuk membangun suatu model 2D adalah membagi sungai kedalam jangkauan sederhana dengan panjang $\Delta l$. Di saat tahap $\Delta t$ dan jangkauan 
sederhana $\Delta l$ bergantung pada kecepatan aliran air $v$, ditulis

$$
\Delta t=\frac{\Delta l}{v}
$$

sedemikian hingga elemen-elemen air berpusat di $l$ pada saat $t$, sehingga pada saat $t+\Delta t$ akan berpusat di $l+\Delta l$.

Misalkan $\beta(t, l)$ dan $\delta(t, l)$ dianggap berturut-turut sebagai kosentrasi BOD dan defisit DO (untuk tingkat kejenuhan), yang terdapat pada jangkauan sederhana sungai, berpusat di $l$ saat $t$. Nilai-nilai BOD dan DO pada $(t+\Delta t, l+\Delta l)$, dihitung dengan suatu persamaan stabil (balance equetion) (Ettore Fornasini, 1996)

$$
\begin{gathered}
\beta((h+1) \Delta t,(k+1) \Delta l) \\
=\left(1-a_{1} \Delta t\right)\left[\beta(h \Delta t, k \Delta l)+M \text { in }_{\beta}(h \Delta t, k \Delta l)\right]
\end{gathered}
$$

dengan mempertimbangkan beberapa hal berikut :

a) Proses penyaringan oleh karena degradasi penyaluran bahan pengotor alam oleh bakteri. Dianggap kosentrasi BOD menurun dengan nilai sama dengan $a_{1} \beta(t, l) \Delta t$, sedangkan defisit DO meningkat, dimana $a_{1}=$ koefisien reoxygenation.

b) Proses reaeration, mengambil ruang pada air/atmofir. Hipotesa dengan menganggap kekurangan DO direduksi dari suatu nilai yang diberikan oleh $a_{2} \delta(t, l) \Delta t$, dimana $a_{2}=$ koefisien reaeration.

c) Sumber BOD (pengaruh runoff lokal, dan lain-lain) dan kemungkinan tumbuhan reoxygenation masingmasing dengan $\beta(.,$.$) dan dengan \delta(.,$.$) .$

Di sini pembahasan didefinisikan untuk masukan BOD dan DO, tidak meliputi variasi pada kecepatan aliran sungai. Defusi dan penyebaran (dispersion) longitudinal tidak diambil kedalam perhitungan nilai-nilai variabel pada titik $(\bar{h} \Delta t, \bar{k} \Delta l)$ dari daerah diskrit

$$
\{(h \Delta t, k \Delta l) \mid(h, k) \in \mathrm{Z} \times \mathrm{Z}\} .
$$

Sekarang misalkan,

$$
\begin{gathered}
x(h, k) \equiv\left[\begin{array}{l}
\beta(h \Delta t, k \Delta l) \\
\delta(h \Delta t, k \Delta l)
\end{array}\right], u(h, k) \equiv\left[\begin{array}{l}
u_{\beta}(h, k) \\
u_{\delta}(h, k)
\end{array}\right] \\
=\left[\begin{array}{c}
i n_{\beta}(h \Delta t, k \Delta l) \\
i n_{\delta}(h \Delta t, k \Delta l)
\end{array}\right],
\end{gathered}
$$

dapat ditulis lagi sebagai suatu model orde kedua 2D,

$$
\begin{aligned}
& x(h+1, k+1) \\
& =\left[\begin{array}{c}
\left(1-a_{1} \Delta t\right)\left[\beta(h \Delta t, k \Delta l)+M \text { in }_{\beta}(h \Delta t, k \Delta l)\right] \\
a_{1} \Delta t \beta(h \Delta t, k \Delta l)+\left(1-a_{2} \Delta t\right)\left[\delta(h \Delta t, k \Delta l)-N \operatorname{in}_{\delta}(h \Delta t, k \Delta l)\right]
\end{array}\right] \\
& =\left[\begin{array}{c}
\left(1-a_{1} \Delta t\right) \beta(h \Delta t, k \Delta l) \\
a_{1} \Delta t \beta(h \Delta t, k \Delta l)+\left(1-a_{2} \Delta t\right) \delta(h \Delta t, k \Delta l)
\end{array}\right] \\
& +\left[\begin{array}{c}
\left(1-a_{1} \Delta t\right) M \text { in }_{\beta}(h \Delta t, k \Delta l) \\
-\left(1-a_{2} \Delta t\right) N \text { in }_{\delta}(h \Delta t, k \Delta l)
\end{array}\right] \\
& =\left[\begin{array}{cc}
1-a_{1} \Delta t & 0 \\
a_{1} \Delta t & 1-a_{2} \Delta t
\end{array}\right]\left[\begin{array}{l}
\beta(h \Delta t, k \Delta l) \\
\delta(h \Delta t, k \Delta l)
\end{array}\right]
\end{aligned}
$$

$$
\begin{gathered}
+\left[\begin{array}{cc}
\left(1-a_{1} \Delta t\right) M & 0 \\
0 & -\left(1-a_{2} \Delta t\right) N
\end{array}\right]\left[\begin{array}{l}
i n_{\beta}(h \Delta t, k \Delta l) \\
i n_{\delta}(h \Delta t, k \Delta l)
\end{array}\right] \\
=\left[\begin{array}{cc}
1-a_{1} \Delta t & 0 \\
a_{1} \Delta t & 1-a_{2} \Delta t
\end{array}\right] x(h, k) u(h, k) \\
+\left[\begin{array}{cc}
\left(1-a_{1} \Delta t\right) M & 0 \\
0 & -\left(1-a_{2} \Delta t\right) N
\end{array}\right] \\
=A_{0} x(h, k)+B_{0} u(h, k)
\end{gathered}
$$

Model 2D di atas dapat lebih dulu sebagai penjajaran dari bentuk sistem 1D tak-hingga, setiap bentuk akan diasosiasikan dengan suatu diagonal berbeda dari daerah diskrit. Volume sederhana dari air pada saat 0 yaitu pada posisi $k \Delta l$, merupakan karakterisasi oleh bagian

$$
\xi(0) \equiv\left[\begin{array}{l}
\beta(0, k \Delta l) \\
\delta(0, k \Delta l)
\end{array}\right]=x(0, k)
$$

Pada saat $i \Delta t$, volume air sepanjang sungai adalah $(k+i) \Delta l$. Kejadian yang berkorespondensi dengan hal tersebut ditulis sebagai

$$
\xi(i) \equiv\left[\begin{array}{l}
\beta(i \Delta t,(k+i) \Delta l) \\
\delta(i \Delta t,(k+i) \Delta l)
\end{array}\right]=x(i, k+i)
$$

dan tenaga masukan (forcing input) adalah

$$
\eta(i) \equiv\left[\begin{array}{l}
u_{\beta}(i, k+i) \\
u_{\delta}(i, k+i)
\end{array}\right]=u(i, k+i) .
$$

Kosentrasi BOD dan defisit (kekurangan) DO dilihat sebagai sesuatu yang harus ditinjau, bahwa sepanjang gerakan dengan volume sederhana air merupakan model sistem 1D mengikuti bentuk :

$$
\begin{aligned}
\xi(i+1) & =x(i+1,(k+i)+1)=A_{0}(i, k+i)+B_{0} u(i, k+i) \\
& =A_{0} \xi(i)+B_{0} \eta(i)
\end{aligned}
$$

Jika model orde pertama 2D yang dipakai, model tersebut memenuhi syarat untuk diperluas ke dimensi ruang bagian. Hal itu terlihat dengan mudah, karena bantuan pesan impuls (impulse response) suatu sistem 2D mengenai dimensi satu, yang mana orthant positif atau satu koordinat dikurangi dimana pesan impuls BOD dan DO ditunjukkan dengan bantuan suatu diagonal. Oleh karena itu dua komponen diperlukan pada vektor bagian lokal untuk menyajikan tingkah laku dinamika dari satu variabel tunggal.

Mengingat pengembangan BOD, misalkan

$$
x_{\beta}(h, k) \equiv\left[\begin{array}{c}
\beta(h \Delta t, k \Delta l) \\
\beta(h \Delta t,(k+1) \Delta l)
\end{array}\right]
$$

adalah vektor bagian lokal pada $(h, k)$. Dengan persamaan stabil didapat

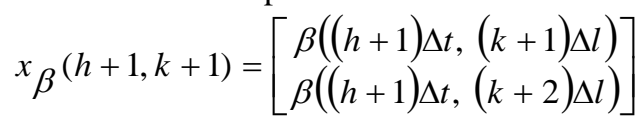




$$
\begin{aligned}
& =\left[\begin{array}{c}
\left(1-a_{1} \Delta t\right)\left[\beta(h \Delta t, k \Delta l)+\operatorname{Min}_{\beta}(h \Delta t, k \Delta l)\right] \\
\left(1-a_{1} \Delta t\right)\left[\beta(h \Delta t,(k+1) \Delta l)+M \text { in }_{\beta}(h \Delta t,(k+1) \Delta l)\right]
\end{array}\right] \\
& =\left[\begin{array}{c}
0 \\
\left(1-a_{1} \Delta t\right) \beta(h \Delta t,(k+1) \Delta l)
\end{array}\right]+\left[\begin{array}{c}
\left(1-a_{1} \Delta t\right) \beta(h \Delta t, k \Delta l) \\
0
\end{array}\right] \\
& +\left[\begin{array}{c}
\left(1-a_{1} \Delta t\right) M \text { in }_{\beta}(h \Delta t, k \Delta l) \\
\left(1-a_{1} \Delta t\right) M \text { in }_{\beta}(h \Delta t,(k+1) \Delta l)
\end{array}\right] \\
& =\left[\begin{array}{cr}
0 & 0 \\
1-a_{1} \Delta t & 0
\end{array}\right]\left[\begin{array}{l}
\beta(h \Delta t,(k+1) \Delta l) \\
\beta(h \Delta t,(k+2) \Delta l)
\end{array}\right] \\
& +\left[\begin{array}{ll}
0 & 1 \\
0 & 0
\end{array}\right]\left[\begin{array}{c}
\beta((h+1) \Delta t, k \Delta l) \\
\beta((h+1) \Delta t,(k+1) \Delta l)
\end{array}\right] \\
& +\left[\begin{array}{c}
0 \\
\left(1-a_{1} \Delta t\right)_{M}
\end{array}\right] \text { in }_{\beta}(h \Delta t, k \Delta l) \\
& =\left[\begin{array}{cc}
0 & 0 \\
1-a_{1} \Delta t & 0
\end{array}\right] x_{\beta}(h, k+1)+\left[\begin{array}{ll}
0 & 1 \\
0 & 0
\end{array}\right] x_{\beta}(h+1, k) \\
& +\left[\begin{array}{c}
0 \\
\left(1-a_{1} \Delta t\right) M
\end{array}\right] u_{\beta}(h, k) \\
& =A_{1 \beta^{X} \beta}(h, k+1)+A_{2 \beta^{X}} \beta^{(h+1, k)+B_{\beta} u} \beta^{(h, k)}
\end{aligned}
$$

dimana suatu orde kedua penunda muncul pada bagian masukan. Kemudian dianggap

$x_{\delta}(h, k) \equiv\left[\begin{array}{c}\delta(h \Delta t, k \Delta l) \\ \delta(h \Delta t,(k+1) \Delta l)\end{array}\right]$,

sehingga

$$
\begin{aligned}
& x_{\delta}(h+1, k+1)=\left[\begin{array}{l}
\delta((h+1) \Delta t,(k+1) \Delta l) \\
\delta((h+1) \Delta t,(k+2) \Delta l)
\end{array}\right] \\
& =\left[\begin{array}{c}
a_{1} \Delta t \beta(h \Delta t, k \Delta l)+\left(1-a_{2} \Delta t\right)\left[\delta(h \Delta t, k \Delta l)-N i n_{\delta}(h \Delta t, k \Delta l)\right] \\
a_{1} \Delta t \beta(h \Delta t,(k+1) \Delta l)+\left(1-a_{2} \Delta t\right)\left[\delta(h \Delta t,(k+1) \Delta l)-N i_{\delta}(h \Delta t,(k+1) \Delta l)\right]
\end{array}\right] \\
& =\left[\left(1-a_{2} \Delta t\right) \delta(h \Delta t,(k+1) \Delta l)\right] \\
& +\left[\begin{array}{c}
\left(1-a_{2} \Delta t\right) \delta(h \Delta t, k \Delta l) \\
0
\end{array}\right]+\left[\begin{array}{c}
0 \\
a_{1} \Delta t \beta(h \Delta t,(k+1) \Delta l)
\end{array}\right] \\
& +\left[\begin{array}{c}
a_{1} \Delta t \beta(h \Delta t, k \Delta l) \\
0
\end{array}\right]+\left[\begin{array}{c}
0 \\
-N\left(1-a_{2} \Delta t\right) i n_{\delta}(h \Delta t,(k+1) \Delta l)
\end{array}\right] \\
& +\left[\begin{array}{c}
-N\left(1-a_{2} \Delta t\right) \operatorname{in}_{\delta}(h \Delta t, k \Delta l) \\
0
\end{array}\right] \\
& =\left[\begin{array}{cc}
0 & 0 \\
1-a_{2} \Delta t & 0
\end{array}\right]\left[\begin{array}{l}
\delta(h \Delta t,(k+1) \Delta l) \\
\delta(h \Delta t,(k+2) \Delta l)
\end{array}\right] \\
& +\left[\begin{array}{ll}
0 & 1 \\
0 & 0
\end{array}\right]\left[\begin{array}{c}
\delta((h+1) \Delta t, k \Delta l) \\
\delta((h+1) \Delta t,(k+1) \Delta l)
\end{array}\right]+\left[\begin{array}{cc}
0 & 0 \\
a_{1} \Delta t & 0
\end{array}\right]\left[\begin{array}{c}
\beta(h \Delta t,(k+1) \Delta l) \\
\beta(h \Delta t,(k+2) \Delta l)
\end{array}\right] \\
& +\left[\begin{array}{c}
0 \\
-N\left(1-a_{2} \Delta t\right)
\end{array}\right] i n_{\delta}(h \Delta t, k \Delta l)
\end{aligned}
$$

$$
\begin{aligned}
= & {\left[\begin{array}{cc}
0 & 0 \\
1-a_{2} \Delta t & 0
\end{array}\right] x_{\delta}(h, k+1)+\left[\begin{array}{ll}
0 & 1 \\
0 & 0
\end{array}\right] x_{\delta}(h+1, k) } \\
& +\left[\begin{array}{cc}
0 & 0 \\
a_{1} \Delta t & 0
\end{array}\right] x_{\beta}(h, k+1)+\left[\begin{array}{c}
0 \\
-N\left(1-a_{2} \Delta t\right)
\end{array}\right] u_{\delta}(h, k) \\
= & A_{1} \delta^{x}(h, k+1)+A_{2 \delta^{x} \delta}(h+1, k) \\
& +A_{\beta \delta^{x}}(h, k+1)+B_{\delta} u(h, k)
\end{aligned}
$$

Berdasarkan (4) dan (6) diperoleh model sebagai berikut:

$$
\begin{aligned}
{\left[\begin{array}{l}
x_{\beta}(h+1, k+1) \\
x_{\delta}(h+1, k+1)
\end{array}\right]=} & \overbrace{\left[\begin{array}{cc}
A_{1 \beta} & 0 \\
A_{\beta \delta} & A_{1 \delta}
\end{array}\right]}^{A_{1}}\left[\begin{array}{l}
x_{\beta}(h, k+1) \\
x_{\delta}(h, k+1)
\end{array}\right] \\
& +\overbrace{\left[\begin{array}{cc}
A_{2 \beta} & 0 \\
0 & A_{2 \delta}
\end{array}\right]}^{A_{2}}\left[\begin{array}{l}
x_{\beta}(h+1, k) \\
x_{\delta}(h+1, k)
\end{array}\right] \\
& +\overbrace{\left[\begin{array}{cc}
B_{\beta} & 0 \\
0 & B_{\delta}
\end{array}\right]}^{B}\left[\begin{array}{l}
u_{\beta}(h, k) \\
u_{\delta}(h, k)
\end{array}\right]
\end{aligned}
$$

Kedua matriks $A_{1}$ dan $A_{2}$ nilpoten, dengan $n=2$. Maka

$$
A_{1}^{i}{ }^{j} A_{2}=0 \text { jika }|i-j|>1 \text {, }
$$

yang mana menyatakan pengembangan sistem (7), sepanjang garis diagonal diskrit, seperti ditunjukkan pada gambar 1. Jelas $A_{1}^{i}{ }^{j} A_{2}=0$ nilpoten untuk $|i-j|>1$, menurut proposisi (Ettore Fornasini, 1994) pasangan $\left(A_{1}, A_{2}\right)$ finite memory dan menurut proposisi (Ettore Fornasini, 1994) pasangan $\left(A_{1}, A_{2}\right)$ separable.

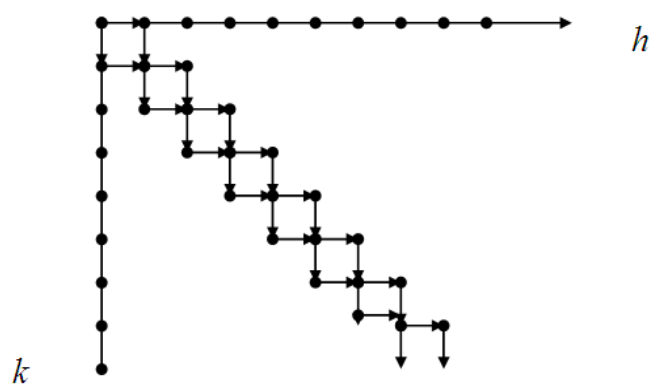

Gambar 1

Sekarang dianggap bahwa pasangan $(h \Delta t, k \Delta l)$ diasosiasikan dengan titik $(a, b) \in \mathrm{Z} \times \mathrm{Z}$ dengan. Jadi titik-titik himpunan terpisah :

$$
C_{\bar{h}} \equiv\{(a, b) \mid a+b=\bar{h}\}
$$

menyajikan lokasi $k \Delta l$ sepanjang bagian sungai pada saat $\bar{h} \Delta t$. Pada bagian lain, titik-titik himpunan

$$
\{(a, b) \mid b=\bar{k}\}=\{(a, \bar{k})\}
$$

diberikan saat $h \Delta t=(a-\bar{k}) \Delta t$ pada lokasi $\bar{k} \Delta l$. 
Misalkan

$$
\begin{gathered}
{\left[\begin{array}{c}
\beta(h \Delta t, k \Delta l) \\
\delta(h \Delta t, k \Delta l)
\end{array}\right] \equiv x(h-k, k)=x(a, b)} \\
{\left[\begin{array}{c}
i n_{\beta}(h \Delta t, k \Delta l) \\
i n_{\delta}(h \Delta t, k \Delta l)
\end{array}\right] \equiv u(h-k, k)=u(a, b)}
\end{gathered}
$$

Dengan demikian maka

$$
\begin{aligned}
& x(h-1, k+1)=\left[\begin{array}{l}
\beta((h-2+1) \Delta t,(k+1) \Delta l) \\
\delta((h-2+1) \Delta t,(k+1) \Delta l)
\end{array}\right] \\
& =\left[\begin{array}{c}
\left(1-a_{1} \Delta t\right)\left[\beta((h-2) \Delta t, k \Delta l)+M \operatorname{in}_{\beta}((h-2) \Delta t, k \Delta l)\right] \\
a_{1} \Delta t \beta((h-2) \Delta t, k \Delta l)+\left(1-a_{2} \Delta t\right)\left[\delta((h-2) \Delta t, k \Delta l)-N \sin _{\delta}((h-2) \Delta t, k \Delta l)\right]
\end{array}\right] \\
& =\left[\begin{array}{c}
\left(1-a_{1} \Delta t\right) \beta((h-2) \Delta t, k \Delta l) \\
a_{1} \Delta t \beta((h-2) \Delta t, k \Delta l)+\left(1-a_{2} \Delta t\right) \delta((h-2) \Delta t, k \Delta l)
\end{array}\right] \\
& +\left[\begin{array}{c}
\left(1-a_{1} \Delta t\right) M \operatorname{in}_{\beta}((h-2) \Delta t, k \Delta l) \\
-\left(1-a_{2} \Delta t\right) N \operatorname{in}_{\delta}((h-2) \Delta t, k \Delta l)
\end{array}\right] \\
& =\left[\begin{array}{cc}
1-a_{1} \Delta t & 0 \\
a_{1} \Delta t & 1-a_{2} \Delta t
\end{array}\right]\left[\begin{array}{l}
\beta(h \Delta t, k \Delta l) \\
\delta(h \Delta t, k \Delta l)
\end{array}\right] \\
& +\left[\begin{array}{c}
\left(1-a_{1} \Delta t\right) M u(h-k, k) \\
-\left(1-a_{2} \Delta t\right) N u(h-k, k)
\end{array}\right] \\
& =\left[\begin{array}{cc}
1-a_{1} \Delta t & 0 \\
a_{1} \Delta t & 1-a_{2} \Delta t
\end{array}\right] x(h-k, k) \\
& +\left[\begin{array}{c}
\left(1-a_{1} \Delta t\right) M \\
-\left(1-a_{2} \Delta t\right) N
\end{array}\right] u(h-k, k)
\end{aligned}
$$

atau ekuivalen dengan

$$
\begin{array}{r}
x(a, b+1)=\left[\begin{array}{cc}
1-a_{1} \Delta t & 0 \\
a_{1} \Delta t & 1-a_{2} \Delta t
\end{array}\right] x(a, b) \\
+\left[\begin{array}{c}
\left(1-a_{1} \Delta t\right) M \\
-\left(1-a_{2} \Delta t\right) N
\end{array}\right] u(a, b)
\end{array}
$$

Dalam gambar 2, garis-garis karakteristik dari sistem pada arah vertikal , $a=$ konstanta

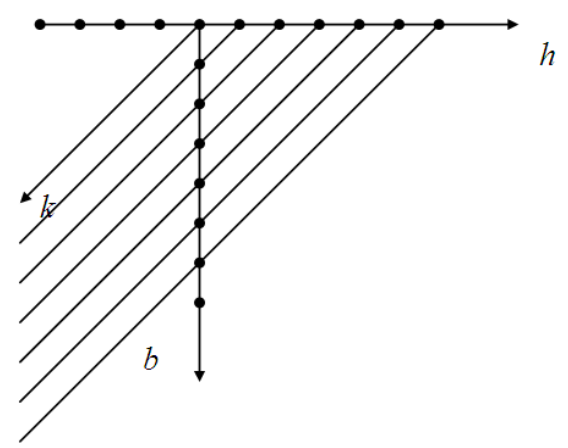

Gambar 2

\section{Kondisi Awal}

Model (1) adalah penjajaran sistem 1D tak-hingga, disusun sepanjang diagonal $\mathrm{Z} \times \mathrm{Z}$. Sebagian besar struktur umum dari kondisi-kondisi awal, konsisten dalam tepat satu bagian lokal pada setiap garis diagonal daerah diskrit. Semua himpunan di atas dalam kondisi dapat dicapai (reachable), oleh karena kondisi itu dapat sebagai gagasan untuk membangun aplikasi sesuai distribusi ruang/waktu dari BOD dan DO.

Penempatan kondisi-kondisi awal dalam model (7), memberikan penyelidikan yang lebih rinci. Pertama-tama komponen bagian lokal menentukan nilai-nilai kosentrasi BOD dan defisit DO pada waktu yang sama dalam dua lokasi ruang berurutan. Selanjutnya kondisi-kondisi awal diberikan pada suatu garis lurus

$$
\{(h, \bar{k}) \mid h \in \mathrm{Z}\}
$$

atau sepanjang batas dari orthant positif. Komponen kedua dan komponen keempat dari $x(h, k)$, mirip dengan komponen pertama dan komponen ketiga dari $x(h, k+1)$.

Lebih jauh aspek struktur dinamik dari sistem itu, bagaimanapun harus diperhatikan karena penetapan bagian-bagian awal adalah penting. Operasi untuk membaharui bagian itu dengan tidak merubah nilai-nilai asli dari kondisi awal pada batasan di atas. Pada bagian future, titik-titik bagian itu tidak konsisten untuk menghitung pengembangan bagian bebas oleh nilai-nilai bagian lokal, ditentukan dengan persamaan

$$
x(h, k)=A_{1}^{h}{ }^{k} A_{2} x(0,0)
$$

Dalam kenyataan mungkin dapat merubah nilai-nilai batasnya, sehubungan dengan itu akan dihitung disini deret kuasa formal (formal power series) yang diasosiasikan dengan bagian barisan indeks kembar, yang ditinjau dalam dua kasus.

Kasus pertama, andaikan bahwa kondisi-kondisi awal diberikan pada batas :

$$
S=\left\{(h, 0) \mid h \in \mathrm{Z}^{+}\right\} \cup\left\{(0, k) \mid k \in \mathrm{Z}^{+}\right\}
$$

dan nilai-nilai masukan (input) pada

$$
\{(h, k) \mid h \geq 0, k \geq 0, h+k>0\}
$$

Oleh karena struktur rekursif, perhitungan $x(\bar{h}, \bar{k}), \bar{h}>0$, $\bar{k}>0$ hanya meliputi bagian lokal awal

$$
\{x(h, 0) \mid 0<h<\bar{h}\} \cup\{x(0, k) \mid 0<k<\bar{k}\}
$$

dan nilai masukan:

$$
\{u(h, k) \mid 0 \leq h<\bar{h}, 0 \leq k<\bar{k}, h+k>0\}
$$

Mengingat deret kuasa formal :

$$
X\left(z_{1}, z_{2}\right) \equiv \sum_{h>0, k>0} x(h, k) z_{1}^{h} z_{2}^{k}
$$

diasosiasikan untuk indeks kembar dari bagian lokal $\left\{x(h, k)_{h, k>0}\right\}$ dan misalkan berkorespondensi dengan $X_{\ell}\left(z_{1}, z_{2}\right)$ disebabkan oleh pengembangan bebas persamaan (10) pada batasan (9), $X_{\ell}\left(z_{1}, z_{2}\right)$ dapat dihitung mengikuti

$$
\begin{aligned}
& X_{\ell}\left(z_{1}, z_{2}\right)=\sum_{h, k>0} x(h, k) z_{1}^{h} z_{2}^{k} \\
& =\sum_{h, k>0}\left\{A_{1} x(h-1, k)+A_{2} x(h, k-1)\right\} z_{1}^{h} z_{2} \\
& =\sum_{i \geq 0, k>0} A_{1} x(i, k) z_{1}^{i+1} z_{2}^{k}+\sum_{h>0, j \geq 0} A_{2} x(h, j) z_{1} z_{2}^{j+1}
\end{aligned}
$$




$$
=\left(I-A_{1} z_{1}-A_{2} z_{2}\right)^{-1}\left[z_{1} A_{1} \sum_{i>0} x(i, 0) z_{1}^{i}+z_{2} A_{2} \sum_{j>0} x(0, j) z_{2}^{j}\right]
$$

pada bagian lain, dengan pengembangan force diperoleh

$$
X_{f}=\left(I-A_{1} z_{1}-A_{2} z_{2}\right)^{-1} B z_{1} z_{2} U\left(z_{1}, z_{2}\right)
$$

dimana

$$
U\left(z_{1}, z_{2}\right) \equiv \sum_{h, k \geq 0} u(h, k) z_{1}^{h} z_{2}^{k}
$$

adalah deret kuasa formal diasosiasikan dengan barisan masukan.

Kasus kedua, dibahas analogis diskrit yang memberikan nilai-nilai pada suatu titik dari sungai (misal pada $l=0$ ) untuk setiap $t$ dalam R. Hal itu berhubungan dalam menentukan model bagian lokal (7) pada garis :

$$
\{(h, 0) \mid h \in \mathrm{Z}\},
$$

nilai-nilai keluaran (output) pada setengah daerah :

$$
\{(h, k) \mid k \geq 0\} \text {, }
$$

dan dalam perhitungan $x(h, k)$ pada setengah daerah :

$$
\{(h, k) \mid k>0\} \text {. }
$$

Suatu peran yang nyata dari kenilpotenan $A_{1}$ dan $A_{2}$ menjamin bahwa suatu bagian lokal tunggal $x(h, k)$ tidak mempengaruhi bagian-bagian lokal pada garis diagonal, yakni tidak memotong himpunan $\{(h, k),(h-1, k),(h+1, k)\}$ mengikuti persamaan yang menyatakan pentingnya sifat itu, dalam menentukan pengembangan bebas dari sistem tersebut (lihat Gambar 3), maka

$$
\begin{aligned}
x(h, 1) & =A_{1} x(h-1,1)+A_{2} x(h, 0) \\
& =A_{1} A_{2} x(h-1,0)+A_{2} x(h, 0) \\
x(h, 2) & =A_{1} A_{2} x(h-1,1)+A_{2} x(h, 1) \\
& =A_{1} A_{2} A_{1} A_{2} x(h-2,0)+A_{2} A_{1} A_{2} x(h-1,0) \\
& \cdots \\
x(h, k)= & \underbrace{A_{1} A_{2} \cdots A_{1} A_{2}}_{2 k \text { faktor }} x(h-k, 0)+\underbrace{A_{2} A_{1} A_{2} \cdots A_{2}}_{2 k-1 \text { faktor }} x(h-k+1,0) \\
= & \left(A_{1}^{k}{ }^{k-1} A_{2}\right) A_{2} x(h-k, 0) \\
& +\left(A_{1}^{k-1}{ }^{k-1} A_{2}\right) A_{2} x(h-k+1,0)
\end{aligned}
$$

Sebagai akibat bentuk (13), jika menggunakan notasi deret kuasa formal, maka

$$
\begin{aligned}
& X\left(z_{1}, z_{2}\right)=\sum_{h>0, k>0} x(h, k) z_{1}^{h} z_{2}^{k} \\
& =\sum_{k \geq 1, h \in Z}\left(A_{1}^{k} \omega^{k-1} A_{2}\right) A_{2} x(h-k, 0) z_{1}^{h} z_{2}^{k} \\
& \quad+\sum_{k \geq 1, h \in Z}\left(A_{1}^{k-1} \omega^{k-1} A_{2}\right) A_{2} x(h-k+1,0) z_{1}^{h} z_{2}^{k} \\
& =\sum_{k \geq 1}\left[\left(A_{1}^{k}{ }^{k-1} A_{2}\right) z_{1}^{k} z_{2}^{k}\right. \\
& \left.\quad+\left(A_{1}^{k-1} \omega^{k-1} A_{2}\right) z_{1}^{k-1} z_{2}^{k}\right] A_{2} \sum_{h \in Z} x(h, 0) z_{1}^{h} \\
& =\left[\sum _ { v \geq 0 } \left[A_{1}^{v+1} \omega^{v} A_{2} z_{1} z_{2}\right.\right.
\end{aligned}
$$

$$
\left.\left.+A_{1}^{v} \omega^{v} A_{2} z_{2}\right] A_{2} z_{1}^{v} z_{2}^{v}\right] \sum_{h \in Z} x(h, 0) z_{1}^{h}
$$

Hal itu membuat anggapan bahwa tingkat BOD dan DO pada bagian sungai ke-0 bergantung pada waktu, yang adalah $x(h, 0)=\bar{x}, \forall h \in \mathrm{Z}$. Bentuk ini dengan jelas diperoleh dari (14) yang merupakan pemecahan yang baik, diberikan oleh

$$
\begin{gathered}
X_{\ell}=\sum_{v \geq 1, h \in Z}\left[A_{1}^{v+1} \omega^{v} A_{2} z_{1} z_{2}\right. \\
\left.+A_{1}^{v} \omega^{v} A_{2} z_{2}\right] A_{2} \bar{x} z_{1} z_{2}^{v} \\
X_{\ell}=\sum_{v \geq 1, h \in Z}\left[A_{1}^{v+1} \omega^{v} A_{2} z_{1}^{h+1} z_{2}{ }^{v+1}\right. \\
\left.+A_{1}^{v} \omega^{v} A_{2} z_{1} z_{2}^{v+1}\right] A_{2} \bar{x}
\end{gathered}
$$

Vektor bagian pada bagian sungai ke- $k$ adalah koefisien sembarang monomial $z_{1}^{*} z_{2}^{k}$ dalam (15), yaitu

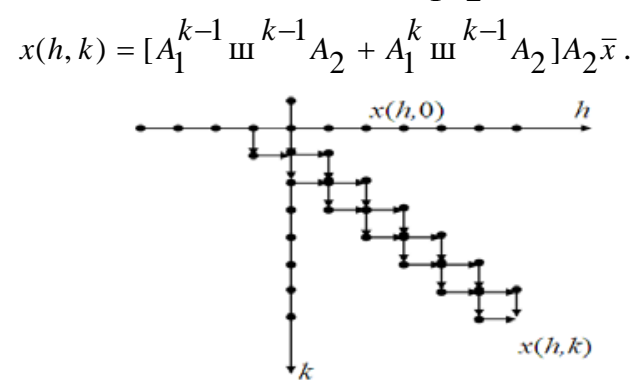

Gambar 3.

\section{Ruang Dependen Dinamik}

Dalam bagian ini dianggap bahwa semua parameter sungai tidak bergantung pada absis $l$. Parameter itu selalu khusus, keanekaragamannya dalam model satu-dimensi berpengaruh kuat dengan sifat-sifat geometri dari model real tiga-dimensi. Dengan mengurangi anggapan pada parameter, dapat mempertinggi beragam kapabilitas untuk fenomena model sungai. Pada bagian akhir nanti akan diandaikan bahwa kecepatan sungai $v$, seperti koefisienkoefisien $a_{1}$ dan $a_{2}$ mungkin bergantung pada $l$.

Tidak sulit memperhitungkan ketergantungan pada $l$ yang mungkin ada. Selain daripada satu kenyataan itu, mengenai variasi-variasi kecepatan $a_{1}$ bergantung pada $l$, mungkin dapat menulis-nya untuk oksidasi bakteri inhomogen (misalnya, variasi yang berkaitan dengan panas atau suatu spesis bakteri yang berlaku lokal pada spesis lain), dan yang bergantung $a_{2}$ mungkin yang berhubungan dengan gerakan putaran air terjun, dan sebagainya, yakni induksi suatu variasi pada proses reaeration.

Ketika kwantitas interval waktu $\Delta t$ menerima konstanta, dengan panjang $\Delta l$ dari jangkauan sederhana, akan dirubah agar supaya memenuhi pada semua kondisi

$$
\Delta t=\frac{\Delta l}{v(l)} \text {. }
$$


Bidang sungai akan dibagi kedalam jangkauan sederhana $\Delta l_{k}=\left[l_{k}, l_{k+1}\right]$, dengan $\Delta l_{k}=v\left(l_{k}\right) \Delta t$

sehingga suatu volume sederhana air pada posisi $l_{k}$, pada saat $t$ dan akan pada posisi $l_{k+1}$ pada saat $t+\Delta t$. Kemudian keluarga $l_{k}$ bergantung pada koefisienkoefisien $a_{1}\left(l_{k}\right)$ dan $a_{2}\left(l_{k}\right)$. Dalam keadaan ini persamaan (1) ditulis sebagai

$x(h+1, k+1)$

$$
\begin{aligned}
& =\left[\begin{array}{cc}
1-a_{1}(k) \Delta t & 0 \\
a_{1}(k) \Delta t & 1-a_{2}(k) \Delta t
\end{array}\right] x(h, k) \\
& \quad+\left[\begin{array}{cc}
{\left[1-a_{1}(k) \Delta t\right] M} & 0 \\
0 & -\left[1-a_{2}(k) \Delta t\right] N
\end{array}\right]\left[\begin{array}{l}
u_{\beta}(h, k) \\
u_{\delta}(h, k)
\end{array}\right] \\
& =A_{0}(k) x(h, k)+B_{0}(k) u(h, k)
\end{aligned}
$$

dimana vektor bagian lokal didefinisikan sebagai

$$
x(h, k) \equiv\left[\begin{array}{l}
\beta\left(h \Delta t, l_{k}\right) \\
\delta\left(h \Delta t, l_{k}\right)
\end{array}\right]
$$

sebagai catatan,

$$
-a_{1}(k) \Delta t \beta\left(h \Delta t, l_{k}\right) \text { dan }-a_{2}(k) \Delta t \delta\left(h \Delta t, l_{k}\right)
$$

menyajikan kosentrasi BOD dan defisit DO, untuk suatu jangkauan sederhana $\left[l_{k}, l_{k+1}\right]$.

Model satu dimensi (2), diasosiasikan dengan (1) maka

$$
\begin{aligned}
\xi(i+1) \equiv & {\left[\begin{array}{c}
\beta((i+1) \Delta t,(k+i+1)) \\
\delta((i+1) \Delta t,(k+i+1))
\end{array}\right]=x((i+1), k+i+1) } \\
= & {\left[\begin{array}{cc}
1-a_{1}(i) \Delta t & 0 \\
a_{1}(i) \Delta t & 1-a_{2}(i) \Delta t
\end{array}\right] x(i, k+i) } \\
& +\left[\begin{array}{cc}
{\left[1-a_{1}(i) \Delta t\right] M} & 0 \\
0 & -\left[1-a_{2}(i) \Delta t\right] N
\end{array}\right] u(i, k+i) \\
= & A_{0}(i) \xi(i)+B_{0}(i) \eta(i)
\end{aligned}
$$

Jika diberikan sembarang $h \Delta t$ (waktu), maka $\xi(i)$ adalah vektor bagian pada absis $l_{i}$ dan pada waktu $(h+i) \Delta t$ akan menghasilkan suatu penetapan vektor bagian $\xi(0)$ pada absis $l_{0}$, dan nilai-nilai masukan $\eta(j)=u\left((h+j) \Delta t, l_{j}\right) ; j=0,1, \cdots$.

Pengembangan bebas bagian $\xi($.$) pada (18),$ memenuhi

$$
\begin{aligned}
& \xi(i+1)=\left[\begin{array}{cc}
1-a_{1}(i) \Delta t & 0 \\
a_{1}(i) \Delta t & 1-a_{2}(i) \Delta t
\end{array}\right]\left[\begin{array}{cc}
1-a_{1}(i-1) \Delta t & 0 \\
a_{1}(i-1) \Delta t & 1-a_{2}(i-1) \Delta t
\end{array}\right] \\
& \ldots\left[\begin{array}{cc}
1-a_{1}(1) \Delta t & 0 \\
a_{1}(1) \Delta t & 1-a_{2}(1) \Delta t
\end{array}\right]\left[\begin{array}{cc}
1-a_{1}(0) \Delta t & 0 \\
a_{1}(0) \Delta t & 1-a_{2}(0) \Delta t
\end{array}\right] \xi(0) \\
& =A_{0}(i) A_{0}(i-1) \quad \cdots \quad A_{0}(1) A_{0}(0) \xi(0)=\Phi(i) \xi(0)
\end{aligned}
$$

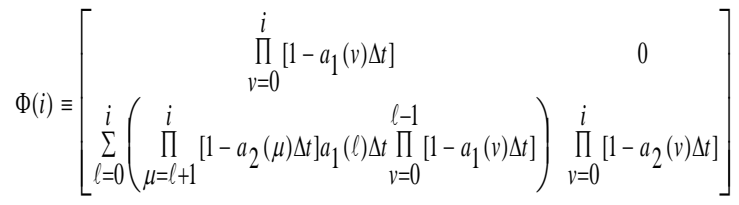

Dengan sifat asimtotik (19), akan dapat menarik kesimpulan dari kriteria konvergenan mutlak untuk suatu perkalian tak-hingga (Knopp 1956), sebab pada kenyataan ketaksamaan

$$
0 \leq a_{1}(v) \Delta t<1, \quad 0 \leq a_{2}(v) \Delta t<1
$$

merupakan syarat perlu dan cukup untuk

$$
\lim _{i \rightarrow+\infty} \prod_{v=0}^{i}\left[1-a_{1}(v) \Delta t\right]=0
$$

dan

$$
\lim _{t \rightarrow+\infty} \prod_{v=0}^{i}\left[1-a_{2}(v) \Delta t\right]=0
$$

keduanya mengikuti deret berbeda berikut

$$
\sum_{v=0}^{+\infty} a_{1}(v)
$$

dan

$$
\sum_{v=0}^{+\infty} a_{2}(v)
$$

Selanjutnya sifat divergen dari (22) merupakan suatu kriteria untuk menjamin hal-hal berikut:

(i). Suatu oksidasi bakteri lengkap dari sembarang muatan injeksi BOD pada bagian $l_{0}$.

(ii). Suatu reareation lengkap dari deoksidasi sungai, jika muatan BOD dianggap nol.

Sekarang akan ditunjukkan bahwa ketika (22) divergen, terminologi pada kedua hal di atas, dalam matriks transisi $\Phi(i)$ konvergen ke nol untuk $i \rightarrow \infty$. Hal ini menunjukkan bahwa divergensi kedua deret (22), merupakan suatu syarat perlu dan cukup untuk penyaringan sungai.

Harus diingat $A_{0}(v)$ dapat sebagai gambaran blok diagonal utama kiri berukuran $2 \times 2$ dari matriks stokastik berukuran $3 \times 3$.

$$
A^{(a)}(v)=\left[\begin{array}{cc:c}
1-a_{1}(v) \Delta t & 0 & 0 \\
a_{1}(v) \Delta t & 1-a_{2}(v) \Delta t & 0 \\
\hdashline 0 & a_{2}(v) \Delta t & 1
\end{array}\right]
$$

Selanjutnya mengikuti langkah-langkah (11) didapat

$$
\begin{aligned}
\Phi^{(a)}(v) \equiv & {\left[\begin{array}{ccc}
1-a_{1}(i) \Delta t & 0 & 0 \\
a_{1}(i) \Delta t & 1-a_{2}(i) \Delta t & 0 \\
0 & a_{2}(i) \Delta t & 1
\end{array}\right] . } \\
& {\left[\begin{array}{ccc}
1-a_{1}(i-1) \Delta t & 0 & 0 \\
a_{1}(i-1) \Delta t & 1-a_{2}(i-1) \Delta t & 0 \\
0 & a_{2}(i-1) \Delta t & 1
\end{array}\right] } \\
& \ldots\left[\begin{array}{ccc}
1-a_{1}(1) \Delta t & 0 & 0 \\
a_{1}(1) \Delta t & 1-a_{2}(1) \Delta t & 0 \\
0 & a_{2}(1) \Delta t & 1
\end{array}\right] .
\end{aligned}
$$




$$
\begin{aligned}
& {\left[\begin{array}{ccc}
1-a_{1}(0) \Delta t & 0 & 0 \\
a_{1}(0) \Delta t & 1-a_{2}(0) \Delta t & 0 \\
0 & a_{2}(0) \Delta t & 1
\end{array}\right]} \\
& =A^{(a)}(i) A^{(a)}(i-1) \quad \cdots \quad A^{(a)}(1) A^{(a)}(0) \\
& =\left[\begin{array}{ll:l}
\Phi(i) & 0 \\
& & 0 \\
\hdashline \phi_{31}^{(a)}(i) & \phi_{32}^{(a)}(i) & 1
\end{array}\right]=\left[\begin{array}{cc:c}
\phi_{11}(i) & 0 & 0 \\
\phi_{21}(i) & \phi_{22}(i) & 0 \\
\hdashline \phi_{31}^{(a)}(i) & \phi_{32}^{(a)}(i) & 1
\end{array}\right]
\end{aligned}
$$

adalah suatu matriks stokastik untuk setiap $i \in \mathrm{Z}^{+}$, dengan

$$
\begin{aligned}
& \phi_{11}(i)=\prod_{v=0}^{i}\left[1-a_{1}(v) \Delta t\right] \\
& \phi_{21}(i)=\sum_{\ell=0}^{i}\left(\prod_{\mu=\ell+1}^{i}\left[1-a_{2}(\mu) \Delta t\right] a_{1}(\ell) \Delta t \prod_{v=0}^{\ell-1}\left[1-a_{1}(v) \Delta t\right]\right) \\
& \phi_{22}(i)=\prod_{v=0}^{i}\left[1-a_{2}(v) \Delta t\right] \\
& \phi_{31}^{(a)}(i)=\sum_{\ell=0}^{i}\left(\prod_{\mu=\ell+1}^{i}\left[1-a_{2}(\mu) \Delta t\right] a_{2}(\ell) \Delta t \prod_{v=0}^{\ell-1}\left[1-a_{1}(v) \Delta t\right]\right)
\end{aligned}
$$

Kemudian dengan menerapkan suatu persamaan rekursif

$\phi_{31}^{(a)}(i+1)=a_{2}(i+1) \Delta t \phi_{21}(i)+\phi_{31}^{(a)}(i)$

mengikuti identitas di atas maka

$$
\begin{aligned}
\phi_{31}^{(a)}(i+1) & =a_{2}(i+1) \Delta t \phi_{21}(i)+a_{2}(i) \Delta t \phi_{21}(i-1)+\cdots+a_{2}(1) \Delta t \phi_{21}(0) \\
& =\sum_{v=1}^{i+1} a_{2}(v) \Delta t \phi_{21}(v-1)
\end{aligned}
$$

Melihat (18), berarti barisan $\left\{\phi_{31}^{(a)}\right\}$ monoton naik. Lagi pula karakter stokastik $\Phi^{(a)}(v)$ menyatakan

$$
\phi_{31}^{(a)}(v) \leq 1, \quad \forall v \in \mathrm{Z}^{+} .
$$

Kejadian menunjukan barisan di atas konvergen ke suatu limit

$$
\begin{gathered}
\bar{\phi}_{31} \in[0,1]: \\
\bar{\phi}_{31}=\lim _{v \rightarrow+\infty} \phi_{31}^{(a)}(v)
\end{gathered}
$$

sekarang dengan mengambil limit kanan $v \rightarrow+\infty$, maka

$$
\lim _{v \rightarrow+\infty} \phi_{11}(v)+\lim _{v \rightarrow+\infty} \phi_{21}(v)+\lim _{v \rightarrow+\infty} \phi_{31}^{(a)}(v)=1
$$

dan mengingat barisan $\left\{\phi_{11}(v)\right\}$ konvergen ke 0 dari (11), maka terlihat barisan $\left\{\phi_{21}(v)\right\}$ akan konvergen ke $\bar{\phi}_{21}=1-\bar{\phi}_{31}$.

Karena diketahui $\bar{\phi}_{21}=0$, berarti kontradiksi dengan $\bar{\phi}_{21}>0$. Maka terdapat suatu bilangan bulat $v_{0}$ sehingga

$$
\phi_{21}(v)>\frac{\bar{\phi}_{21}}{2}, \quad \forall i \geq v_{0}
$$

dan oleh karena itu dengan (26) maka

$$
\phi_{31}^{(a)}\left(i+1+v_{0}\right) \geq \sum_{v=v_{0}}^{v_{0}+1} a_{2}(v+1) \Delta t \phi_{21}(v) \geq \frac{\bar{\phi}_{21}}{2} \Delta t \sum_{v=v_{0}}^{v_{0}+1} a_{2}(v+1)
$$

Dengan memperhitungkan deret $\sum_{v} a_{2}(v)$ divergen, maka barisan $\left\{\phi_{31}^{(a)}(v)\right\}$ juga akan divergen, yang mana kontradiksi , karena $\bar{\phi}_{31}>0$ berhingga. Selanjutnya

$$
\bar{\phi}_{21}=0
$$

dan

$$
\Phi(i) \rightarrow 0 \text { untuk } i \rightarrow \infty
$$

\section{KESIMPULAN}

Dari pembahasan dapat disimpulkan bahwa:

1. Membangun suatu model $2 \mathrm{D}$ adalah membagi sungai kedalam jangkauan sederhana dengan panjang $\Delta l$. Di saat tahap $\Delta t$ dan jangkauan sederhana $\Delta l$ bergantung pada kecepatan aliran air $v$, ditulis $\Delta t=\Delta l / v$, dengan mempertimbangkan proses penyaringan, proses reaeration, dan sumber BOD (pengaruh runoff lokal, dan lain-lain) diperoleh model orde kedua $2 \mathrm{D}$

$$
\begin{aligned}
x(h+1, k+1) & =\left[\begin{array}{c}
\left(1-a_{1} \Delta t\right)\left[\beta(h \Delta t, k \Delta l)+M \text { in }_{\beta}(h \Delta t, k \Delta l)\right] \\
a_{1} \Delta t \beta(h \Delta t, k \Delta l)+\left(1-a_{2} \Delta t\right)\left[\delta(h \Delta t, k \Delta l)-N i n_{\delta}(h \Delta t, k \Delta l)\right]
\end{array}\right] \\
& =A_{0} x(h, k)+B_{0} u(h, k)
\end{aligned}
$$

2. Pengembangan BOD, dengan misalkan

$$
x_{\beta}(h, k) \equiv\left[\begin{array}{c}
\beta(h \Delta t, k \Delta l) \\
\beta(h \Delta t,(k+1) \Delta l)
\end{array}\right]
$$

adalah vektor bagian lokal pada $(h, k)$. Dengan persamaan stabil didapat

$$
\begin{aligned}
x_{\beta}(h+1, k+1) & =\left[\begin{array}{c}
\beta((h+1) \Delta t,(k+1) \Delta l) \\
\beta((h+1) \Delta t,(k+2) \Delta l)
\end{array}\right] \\
& =A_{1 \beta} x_{\beta}(h, k+1)+A_{2 \beta} x_{\beta}(h+1, k)+B_{\beta} u_{\beta}(h, k)
\end{aligned}
$$

\section{DAFTAR PUSTAKA}

Bose, N.K., 1982, Applied Multidimentional system Theory, Van Nostrand Reinhold, New York

Bisiacco, M., 1985, State and output feedback stabilizability of 2D systems, IEEE Trans. Circ. Sys., vol CAS-32, pp. 1246-54.

Fornasini,E. and Machesini,G., 1976, State-Space Realization Theory Of Two-Demensional Filters, IEEE Trans.Aut.Contr,vol.AC-21,484-492.

Fornasini,E. and Machesini,G., 1978, Doubly-Indexed Dynamical systems : State-Space Models and Tructural Properties, Math.Systems .Teory, vol. 12, 59-72.

Fornasini,E., Marchesini,G., and Valcher,M.E., 1994, On The Structure of Finite Memory and Separable Two-Dimensional Systems, Automatica, vol. 30, 347-350. 
Fornasini,E., and Valcher,M.E.,1994, Matrix Pairs in Two-Dimensional Systems : an Approach Based on Trace Series an Hankel Matrices, to appear in SIAM J. Contr.Opt.

Fornasini,E., 1991, A 2D systems approach to river pollution modelling, Multid. Sys. Sign. Process., 2, pp.233-65

Luenberger, D.G., Introduction to dynamical systems, J. Wiley \& Sons Inc., 1979.

Motzkin,T.S., and Taussky,O., 1952, Pairs of Matrices With property L(1), Trans.Amer.Scc., vol.73. 108114.

Orlob, G.T,. 1983, Mathematical Modeling of Water Quality: Steams, Lakes, dan Reservoirs, International Institute for Applied Systems Analysis.

Valcher,M.E., and Fornasini,E., 1994, State Models and Asymptotic Behavior of Two-Dimensional Positive Systems, to Appear in IMA J. of Appl.Math. 